\title{
A EDUCAÇÃO PROFISSIONAL E TECNOLÓGICA NA MODALIDADE A DISTÂNCIA: HISTÓRIA, BASES LEGAIS E CURSOS NESSA MODALIDADE DE ENSINO
}

\author{
H. C. SILVA* e M. L. F. COSTA** \\ Universidade Estadual de Maringá - Maringá-PR \\ helencamila@hotmail.com* \\ luisafurlancosta@gmail.com**
}

Artigo submetido em fevereiro/2017 e aceito em abril/2017

DOI: $10.15628 /$ rbept.2017.5716

\section{RESUMO}

Este artigo, de cunho bibliográfico, é resultado parcial da dissertação de mestrado na linha de pesquisa de História e Historiografia da Educação do Programa de Pós-Graduação em Educação da Universidade Estadual de Maringá (UEM), que teve como objeto de estudo a Educação Profissional e Tecnológica na modalidade a distância. Esta proposta de estudo objetiva discorrer sobre os aspectos históricos e legais da educação profissional e tecnológica a distância, além de apresentar o desenvolvimento dos cursos dessa modalidade de ensino em algumas instituições, como o Instituto Monitor, o Instituto Universal Brasileiro, o
Telecurso e a Rede e-TEC, demonstrando a importância dessas práticas de ensino e aprendizagem. Destacamos que a modalidade de educação a distância tem conquistado, nas últimas décadas, um enfoque de destaque no centro das atenções pedagógicas, uma vez que torna possível o acesso de indivíduos que sem ela não teriam condições de frequentar salas de aula presenciais para buscar formação. Assim, a Educação Profissional e Tecnológica na modalidade a distância configura-se como uma estratégia de expansão do ensino que possibilita a formação dos sujeitos ao longo da vida.

PALAVRAS-CHAVE: Educação Profissional e Tecnológica, Educação a Distância.

\section{PROFESSIONAL AND TECHNOLOGICAL DISTANCE EDUCATION: HISTORY, LEGAL BASIS AND COURSES IN THIS LEARNING MODALITY}

\begin{abstract}
This article, of bibliographical nature, is a partial result of the master's degree dissertation of the Education History and Historiography research line of the PostGraduation in Education Program of the State University of Maringa (UEM) that had as study object Professional and Technological Distance Education. This study proposal's objective is to discourse on the historical and legal aspects of professional and technological distance education, in addition to present the development of the courses in this learning modality in some institutions, such as Instituto Monitor, Instituto
\end{abstract}

Universal Brasileiro, Telecurso and Rede e-TEC, demonstrating the importance of these teaching and learning practices. The distance learning modality has been highlighted in the last decades on the center of pedagogical attention, once it makes possible the access to individuals who would not have conditions to attend presential classrooms to seek education. Therefore, Professional and Technological Distance Education is established as a strategy for expanding learning that enables lifelong education for people.

KEYWORDS: Professional and Technological Education, Distance Education. 


\section{INTRODUÇÃO}

Este artigo é resultado parcial da dissertação de mestrado da linha de pesquisa de História e Historiografia da Educação do Programa de Pós-Graduação em Educação da Universidade Estadual de Maringá (UEM), que teve como objeto de estudo a Educação Profissional e Tecnológica na modalidade a distância. Trata-se de uma pesquisa bibliográfica que, de acordo com Gil (2010, p. 29), "é aquela elaborada com base em material já publicado".

Esta proposta de estudo tem como objetivo discorrer sobre os aspectos históricos e legais da educação profissional e tecnológica a distância, além de apresentar o desenvolvimento dos cursos de Educação Profissional e Tecnológica nessa modalidade em algumas instituições de ensino como o Instituto Monitor, o Instituto Universal Brasileiro, o Telecurso e a Rede e-TEC, demonstrando a importância dessas práticas de ensino e aprendizagem. O que nos motivou a elaborar este texto foi nossa vivência no mestrado, nossa prática profissional e a percepção da relevância da Educação Profissional e Tecnológica na modalidade a distância no contexto atual do mundo do trabalho em nosso país. Pontuamos que a educação profissional marcou as práticas humanas desde as sociedades mais primitivas, quando os conhecimentos profissionais eram transmitidos por meio da observação, da prática e da repetição. No decorrer da história, a Educação Profissional e Tecnológica adquiriu diversas funções, embasada por inúmeras leis e decretos que estabeleceram suas práticas pedagógicas e a sua estrutura.

A globalização e as inovações tecnológicas têm alterado significativamente o processo produtivo, gerando mudanças no desempenho laboral. Diante disso, o processo educacional se apresenta como um caminho que possibilita o indivíduo, no patamar da empregabilidade, uma educação que tem se adequado aos padrões de formação exigidos pela modernidade.

Nesse sentido, destacamos que os profissionais devem buscar constantemente uma formação, inicial ou continuada, frente à necessidade que o mundo do trabalho exige, além de satisfazer o interesse de crescimento profissional e pessoal. 0 trabalhador, que antes conseguia uma inserção no mercado com apenas o Ensino Médio, hoje deve estar em permanente formação visando seu aprimoramento profissional, atendendo, assim, às novas demandas sociais, que solicita uma formação sólida e adequada ao seu contexto de trabalho.

Compreendemos então que, para responder à demanda do mundo do trabalho, é necessário proporcionar ao trabalhador formação específica e adequada às necessidades de sua área de atuação, que extrapole a aplicação técnico-profissional e possibilite conhecimentos científicos e tecnológicos que propiciarão melhores condições para sua inserção no cenário produtivo do século XXI. Assim, os processos de transformação estimulados pela reestruturação tecnológica nos fazem evidenciar a necessidade de se criar novas estratégias de ensino e aprendizagem para atender às demandas recorrentes.

Nesse contexto, a modalidade de educação a distância tem conquistado, nas últimas décadas, um enfoque de destaque no centro das atenções pedagógicas, uma vez que torna possível o acesso de indivíduos que sem ela não teriam condições de frequentar salas de aula 
presenciais para buscar formação. Salientamos que a Educação Profissional e Tecnológica na modalidade a distância configura-se como uma estratégia de expansão do ensino.

Discorrer acerca do histórico da educação profissional e tecnológica a distância e apresentar algumas iniciativas de instituições que viabilizam essa modalidade de ensino nos permitem entender a importância da EaD na formação profissional do homem contemporâneo, que necessita estar qualificado e atento às novas possibilidades que a crescente evolução tecnológica oferece aos bens e serviços. Esse é o nosso propósito neste artigo.

\section{ASPECTOS HISTÓRICOS E LEGAIS DA EDUCAÇÃO PROFISSIONAL E TECNOLÓGICA NA MODALIDADE A DISTÂNCIA}

A Educação Profissional e Tecnológica foi inserida na modalidade a distância quando, por meio de iniciativas do Instituto Monitor e do Instituto Universal Brasileiro, estabeleceram no país cursos a distância com a utilização de materiais impressos. Mais tarde, estimulada pelas tecnologias de comunicação e informação propiciadas pelo rádio e televisão, a Fundação Roberto Marinho criou os programas Telecurso de 10 Grau e Telecurso de $2^{\circ}$ Grau e também o Telecurso 2000, este último voltado especificamente a cursos profissionalizantes.

É possível percebermos que, embora as iniciativas de educação profissional e tecnológica na modalidade a distância no Brasil ocorram desde meados do século $X X$, é apenas com a promulgação da LDBEN/96, do Decreto 2.494/98, do Decreto 2.561/98, do Decreto 5.622/05, do Decreto 6.301/07 e do Decreto 7.589/11 que essa modalidade de ensino passa a ter caráter legal e é tratada como parte do sistema educacional brasileiro. Assim, ao discorrermos sobre o histórico da Educação a Distância no Brasil, acreditamos ser possível entender o processo de construção da educação profissional e tecnológica nessa modalidade de ensino.

O desenvolvimento histórico da Educação a Distância, no Brasil e no mundo, é marcado pelo surgimento e disseminação dos meios de comunicação. Em um primeiro momento, passamos pela etapa do ensino por correspondência. Vale ressaltar que o uso das mensagens escritas com fins educativos teve origem na Antiguidade, inicialmente na Grécia e Roma, e por meio das cartas eram transmitidas informações científicas a discípulos que se encontravam distantes de seus mestres (SARAIVA, 1996).

Com a evolução tecnológica, um novo paradigma se configura na Educação a Distância, surge a etapa radiofônica, televisiva e nos dias de hoje a internet. Para compreender a EaD enquanto modalidade de ensino, é necessário tratarmos das práticas educativas desenvolvidas de modo a visualizarmos seu processo de construção.

As ações institucionalizadas de Educação a Distância iniciaram-se em meados do século XIX, com a criação das primeiras escolas por correspondência destinadas ao ensino de línguas, a cursos de contabilidade ou de extensão universitária em países como Alemanha, Inglaterra, Estados Unidos e Suécia (SARAIVA, 1996). Entre meados do século XIX até o início do século XXI na Europa, a EaD percorreu um horizonte temporal de mais de 150 anos, perpassando pela educação 
por correspondência até a utilização de ferramentas como as Tecnologias de Informação e Comunicação (TIC) (RIBEIRO, 2008).

No Brasil, não há consenso sobre o início da Educação a Distância; no entanto, Alves (2011) aponta o ano de 1891 como uma referência quando a mídia impressa, com grande circulação na cidade do Rio de Janeiro, o "Jornal do Brasil" traz em seus classificados anúncios ofertando o curso de datilógrafo por correspondência. Já em 1904, tem-se a implantação das Escolas Internacionais, instituições de ensino privadas que ofereciam cursos nesse formato.

A maioria dos estudiosos considera a década de 1920 como marco histórico inicial da Educação a Distância no Brasil quando Edgard Roquette-Pinto, seguro da relevância cultural da rádio, defende essa ferramenta de comunicação enquanto meio de oferta educacional à população brasileira. Em 1923, é fundada pela Academia Brasileira de Ciências e administrada por Edgard Roquette-Pinto a Rádio Sociedade do Rio de Janeiro que, mais tarde, em 1936, foi doada ao Ministério da Educação e Saúde que a utiliza em 1937 para a criação do Serviço de Rádio Difusão Educativa do Ministério da Educação (ALVES, 2011).

Com o objetivo de universalizar a formação profissional é implantado, no ano de 1939, o Instituto Rádio Técnico Monitor, dando ênfase ao ensino da eletrônica. Em seu sítio oficial, o Instituto informa que foi pioneiro na oferta de cursos profissionalizantes a distância. Já em 1941, ganha destaque o Instituto Universal Brasileiro, fundado pelo ex-sócio do Instituto Rádio Técnico Monitor, que já formou, de acordo com Alves (2011), mais de 4 milhões de alunos. Ambas as instituições mantinham a correspondência como instrumento pedagógico.

Vale destacar que essas duas instituições, o Instituto Rádio Técnico Monitor, hoje denominado Instituto Monitor, e o Instituto Universal Brasileiro mantêm-se ativas até a presente data, ofertando educação a distância em diversos níveis, abrangendo o Ensino Fundamental e Médio por meio da oferta do curso supletivo e cursos profissionalizantes de qualificação e técnico, o que pode ser confirmado no sítio oficial das instituições.

Ainda sobre a década de 1940, com o objetivo de universalizar a Educação a Distância, é implantada, em São Paulo, a Universidade do Ar, difundida via rádio pela emissora Rádio Nacional do Rio de Janeiro com vistas à orientação metodológica de docentes do ensino secundário por meio dos "[...] cursos de letras, ciências, didática e pedagogia, entre outros, abertos a todos os professores do país" (MOREIRA, 1991, p.19). Mais tarde, em 1947, Alves (2011) pontua que a Universidade do Ar é incorporada pelo Serviço Nacional de Aprendizagem Comercial (SENAC), que em conjunto com o Serviço Social do Comércio (SESC) e demais emissoras associadas, ofertavam cursos comerciais radiofônicos na modalidade a distância.

Linden e Assis (2008) atestam que entre as décadas de 1950 e 1960 houve um grande avanço dos cursos via correspondência, propiciando a formação inicial por meio da alfabetização de jovens e adultos. Além disso, a Igreja Católica institui o Movimento de Educação de Base (MEB), organismo vinculado à Conferência Nacional dos Bispos do Brasil (CNBB) com apoio do governo federal o qual buscou levar, com auxílio da televisão e do rádio, a alfabetização até a população mais pobre das regiões norte e nordeste do país. 
Nessa mesma linha, citamos dois grandes projetos que contribuíram para a democratização do ensino a distância no país, a saber, o Projeto SACl e o Projeto Minerva. Em 1969, o Projeto Satélite Avançado de Comunicações Interdisciplinares, o Projeto SACl, promulgado pelo Instituto de Pesquisas Espaciais do Conselho Nacional de Desenvolvimento Científico e Tecnológico (CNPq), oportunizou aulas pré-gravadas aos alunos das séries iniciais e também a professores que atuavam em sala de aula e que não tinham formação específica necessária. Em 1970, o Projeto Minerva ocupava-se em educar de forma continuada jovens e adultos, propiciando a formação em nível de primeiro grau (SARAIVA, 1996).

Já nos anos de 1970 e 1980, a televisão entra em cena, ofertando oportunidade de conclusão do ensino básico integrando conteúdos do Ensino Fundamental e Médio. É nesse período que a Fundação Roberto Marinho, em conjunto com a Fundação Padre Anchieta, passa a produzir e transmitir em televisão aberta o "Telecurso 20 Grau", utilizando como material didático fascículos impressos e teleaulas. Em 1971, segundo sítio oficial da Fundação Roberto Marinho, em continuidade às iniciativas do Telecurso 2 Grau, institui-se o "Telecurso 1 Grau", exibido por quatorze anos, sendo extinto com a criação do "Telecurso 2000", na década de 1990.

Nas décadas de 1970 e 1980, conforme Pimentel (2006), diversos projetos de lei foram apresentados para a criação da Universidade Aberta do Brasil (UAB), mas sem a efetivação de nenhum deles. A UAB é um programa do Ministério da Educação em parceria com instituições federais, estaduais e municipais e foi regulamentado pelo Decreto $\mathrm{n}-5.800$, de 8 de junho de 2006. A UAB não é uma instituição de ensino e sim um sistema de parceria que tem como objetivo estimular a articulação e integração do Ensino Superior a distância, visando à expansão e interiorização da educação superior em polos municipais de apoio presencial. Nos anos de 1980, segundo Linden e Assis (20008), a Universidade de Brasília e a Fundação Roberto Marinho promoveram diversos cursos de educação a distância; enquanto a primeira tinha foco na oferta de cursos de extensão universitária, a segunda oportunizava cursos supletivos com vistas à formação de primeiro e segundo graus.

Somente em 1996, com a instituição da Lei de Diretrizes e Bases da Educação Nacional 9.394, de 20 de dezembro de 1996, é que a modalidade de Educação a Distância tem as suas bases legais apresentadas no Artigo no 80, que orienta e define a possibilidade da oferta de cursos na modalidade a distância. Embora um artigo de lei que regulamentasse a modalidade de educação a distância tenha sido um grande avanço, este por si só não respaldava todas as particularidades de que essa modalidade de ensino necessitava. Assim, em 1998, o Decreto 2.494 surge para regulamentar o Artigo 80 da LDBEN/1996 e traz em seu texto disposições sobre o conceito, as normas e a organização dos cursos ofertados nessa modalidade (BRASIL, 2005).

Em 27 de abril de 1998, o Decreto 2.561 altera a redação dos artigos 11 e 12을 do Decreto $2.494 / 98$, regulando sobre os atos de credenciamento das instituições que ofertam os cursos a distância para jovens e adultos com cursos de ensino médio e educação profissional de nível técnico e de nível tecnológico do ensino superior. Vale salientar que esses documentos vigoraram por aproximadamente sete anos, até 20 de dezembro de 2005, quando foram revogados pelo Decreto 5.622, que além de regulamentar o artigo 80 da LDBEN/1996 e traçar as normas para 
realização dos cursos na modalidade a distância, trata do envolvimento das TICs enquanto instrumento de acesso ao ensino.

Com a revolução tecnológica gerada pela utilização de computadores e posteriormente pela internet, começaram a surgir novas ferramentas de interação para a Educação a Distância. A esse respeito, Ribeiro (2008, p. 43) afirma que:

[...] foi com o surgimento da comunicação mediada por computador que o potencial da educação a distância se redimensionou aceleradamente. $O$ impacto da internet redefiniu papéis em todos os setores, e a educação não ficou de fora, com as aplicações de correio eletrônico, bate-papo, fóruns, etc., permitindo que os interessados se comunicassem de forma síncrona e assíncrona.

O advento da internet, ao revolucionar os setores sociais, incluindo o setor educacional, acaba por propiciar a disseminação da EaD nas instituições de ensino, promovendo o registro e credenciamento de diversas instituições para atuar nessa modalidade.

Ainda para Ribeiro (2008, p. 43), “[...] a atual geração da educação a distância promete revoluções ainda mais intensas, a popularização das redes wireless com seus hotspots se espalhando [...] irão impactar diretamente nas possibilidades da EaD”. E Ribeiro e Antunes (2013, p. 8) observam:

As novas tecnologias interativas têm produzido grande impacto na sociedade, alterando relações de tempo e espaço no trabalho, no lazer e nas relações sociais. Compreender o aluno que vive essa nova realidade, suas necessidades e especificidades, inseridas em um contexto socioeconômico e cultural, e assim atendê-lo e formá-lo adequadamente e eficazmente, é um grande desafio da escola contemporânea. Não há como ignorar as novas linguagens, culturas e hábitos dos jovens, para os quais a separação entre virtual e real é cada vez mais tênue. É bastante previsível, pois, que essa convergência entre real e virtual na educação seja fato inexorável. A tendência de combinar atividades de aprendizagem face a face com atividades desenvolvidas a distância - em geral online- vem sendo referida por meio de diversas denominações, das quais destacamse 'cursos híbridos' e blended learning."

A EaD está em constante desenvolvimento e cada vez mais evidenciada como uma modalidade de ensino. Esse processo acontece principalmente devido à influência do meio, o espaço e das tecnologias de informação e comunicação. Nesse sentido, a educação profissional e tecnológica nessa modalidade configuram-se como uma estratégia de expansão do ensino.

O Decreto 6.301, de 12 de dezembro de 2007, constituiu o Sistema Escola Técnica Aberta do Brasil - e-Tec Brasil - e propôs a ampliação da oferta e a democratização do acesso ao ensino técnico, público e gratuito na modalidade a distância. Esse Decreto foi revogado em 26 de outubro de 2011 pela Presidente da República Dilma Rousseff e pelo Ministro da Educação Fernando Haddad quando publicaram o Decreto 7.589 instituindo a Rede e-Tec Brasil com o objetivo de desenvolver a educação profissional e tecnológica na modalidade de educação a distância pública e gratuita. Em síntese, podemos perceber que a LDBEN/96 e os Decretos apresentados fortaleceram o crescimento da oferta de cursos a distância no país, pois essa modalidade de 
ensino adquiriu regulamentação própria e passou a ter critérios para a criação de cursos ou programas na modalidade a distância em todos os níveis educacionais.

Dessa forma, entendemos que a Educação a Distância desponta como uma modalidade de ensino que flexibiliza a aprendizagem. A exemplo de iniciativas que atuam na Educação Profissional e Tecnológica na modalidade a distância com esse objetivo de flexibilização, citamos as instituições Instituto Monitor e o Instituto Universal Brasileiro, além dos programas Telecurso e Rede e-Tec, este último por meio do PRONATEC, programa que não nos atemos neste estudo.

\section{O INSTITUTO MONITOR}

Na década de 1920, iniciou-se no Brasil a difusão do rádio. A primeira transmissão radiofônica aconteceu no dia 7 de setembro de 1922 como parte das comemorações do Centenário da Independência. Nesse período foi instalada, no Rio de Janeiro, uma estação inaugurada com um discurso do presidente Epitácio Pessoa.

Com o objetivo de universalizar a formação profissional para atender à demanda de mão de obra especializada para manusear os equipamentos eletrônicos da época e com os reflexos da crise de 1929 na agricultura brasileira que afetou positivamente a indústria brasileira, o imigrante húngaro Nicolás Goldberger instalou uma empresa em São Paulo especializada em conhecimentos de eletrônica realizando sua propagação via rádio. Vislumbrando atingir grande parte do território brasileiro com os seus conhecimentos, Goldberger fundou o "Instituto Monitor" em 1939. Segundo Torres (2009), a nomenclatura inicial dada à instituição foi "Instituto Rádio Técnico Monitor", sendo esta a escola pioneira no Brasil a desenvolver a educação a distância na educação profissional.

Como ainda não existiam pessoas qualificadas para o manejo de tais aparelhos radiofônicos, nasceu o primeiro curso a distância por correspondência na área de eletrônica, composto por algumas apostilas e um kit didático contendo componentes eletrônicos que possibilitavam construir um modesto rádio caseiro. Dessa maneira, com o objetivo de preparar técnicos em instalação, conserto e montagem, os cursos oferecidos pelo Instituto Monitor visavam preparar pessoas tanto nos grandes centros como em locais de difícil acesso, capacitando-os para oferecer a necessária assistência técnica. Após realizar a inscrição, o aluno recebia via correspondência manuais contendo lições teóricas sobre o curso e um Kit didático que lhe possibilitava desenvolver as lições práticas. O curso era baseado em situações em que o aluno aprendia sua profissão por meio de tarefas teóricas-práticas.

Em seu site oficial, o Instituto Monitor informa que propiciou uma crescente área mercadológica em seu entorno. A necessidade de equipamentos e ferramentas transformou a região da Santa Efigênia, em São Paulo, em um grande polo referência de comércio e distribuição de peças de eletrônica, o que permanece até os dias atuais. Na atualidade, o Instituto Monitor possui três unidades educacionais nos estados de São Paulo, Rio de Janeiro e Paraná, todas interligadas via internet. Desde 2007, a instituição oferece cursos on-line em diversas áreas de atuação, abrangendo o Ensino Fundamental e Médio por meio da oferta do curso supletivo e cursos profissionalizantes de qualificação e técnico. 


\section{O INSTITUTO UNIVERSAL BRASILEIRO}

Na mesma linha do Instituto Monitor, em 16 de outubro de 1941 é fundada a segunda escola de educação profissional a distância no país, o Instituto Universal Brasileiro - IUB, pelos irmãos Jacob Warghafting e Michael Warghafting. Sobre o início desse instituto, Faria (2010) discorre:

O início da história do IUB está ligado a do Instituto Monitor, uma vez que um dos seus fundadores tinha sido sócio proprietário do Instituto Monitor, o qual após desfazer a sociedade, fundou, com seu irmão, o IUB. O IUB iniciou atuando na formação de mão-de-obra para o setor industrial e de serviços, mas logo a seguir passou a ofertar cursos que exerciam o papel de "suplência", uma vez que, preparavam os alunos para jovens e adultos prestar os exames de natureza ginasial e colegial (FARIA, 2010, p. 82).

O objetivo inicial do Instituto era lançar o curso de contabilidade nas páginas da Revista "O Cruzeiro", revista semanal ilustrada lançada no Rio de Janeiro em 10 de novembro de 1928, visando preparar jovens e adultos para o mercado de trabalho. O correio foi o primeiro instrumento usado no ensino a distância por esse instituto. Segundo Faria (2010, p. 17):

[...] o IUB foi um dos grandes expoentes em cursos de pequena duração a distância utilizando como suporte pedagógico a correspondência, assim o envio das "cartilhas" e dos manuais era realizado pelo IUB via correio e seus alunos devolviam as "lições" respondidas pelo mesmo correio, utilizando o correspondência como mediador deste processo de ensino e aprendizagem.

Nos anos seguintes, foram implantados outros cursos, com destaque para Rádio e TV, Corte e Costura, Desenho Artístico, Mecânica de Automóveis e Auxiliar de Escritório, totalizando 35 cursos. Nesse sentido, o Instituto se tornou a maior escola de Ensino Profissional a Distância do país entre as décadas de 1960 e 1980. Faria (2010, p. 18 e 19) aponta:

[...] desde os primeiros anos o IUB, oferece dois "tipos" de cursos: de um lado os cursos livres, ou cursos informais; de outro lado os cursos formativos educacionais ou cursos regulamentados por lei. Os primeiros cursos informais foram os cursos de datilografia, taquigrafia, estenografia e eletrônica em Rádio. Após alguns anos foi lançado o primeiro curso regulamentado por lei, o curso de ensino ginasial denominado de Madureza Ginasial que teve conotação preparatória para a prestação de Exames de madureza Ginasial criados pelo Decreto Lei № 4.244 de 9 de abril de 1942.

As divulgações dos cursos a distância pelo Instituto Universal Brasileiro chamavam a atenção do leitor para diversas possibilidades de inserção ao mercado de trabalho, além de atribuir ao Instituto a credibilidade de possibilitar ascensão profissional aos indivíduos que se matriculavam nos cursos oferecidos. Para que o aluno realizasse o conserto e a manutenção de televisão e rádio, o Instituto fornecia o material didático completo, que incluía Kit de rádio, multímetro e 30 apostilas com as informações necessárias acerca do funcionamento desses aparelhos eletrônicos.

Além dos cursos de Televisão, Rádio e Eletrônica, havia o curso de Madureza Ginasial que teve conotação preparatória para a prestação de Exames de Madureza Ginasial criados pelo 
Decreto-Lei no 4.244, de 9 de abril de 1942, e também o Curso de Caligrafia. Assim, o ensino a distância abrangia, também, o ensino escolar, além dos cursos técnicos e profissionalizantes (FARIA, 2010). É importante destacar que o Instituto concebe a educação a distância como uma possibilidade viável na construção de mecanismos que favoreçam a aprendizagem e a qualificação profissional contínua ao longo da vida, bem como apresenta condições de ensino adequadas para jovens e adultos.

Atualmente, o Instituto desenvolve cerca de 40 cursos, atendendo às áreas de Corte e Costura, Mestre de Obras, Bolos Decorados, Refrigeração e Ar Condicionado, Montagem e Manutenção de Computadores, entre outros, e também Cursos Técnicos (Transações Imobiliárias, Secretariado, Secretaria Escolar e Gestão Comercial) e Supletivo. As informações referentes aos cursos disponíveis, contatos e matrículas podem ser acessadas pelos alunos por meio da página oficial na internet. Essa página conta com links para acesso aos diferentes cursos e informações pertinentes à matrícula e conclusão.

Observamos que, ainda hoje, esses dois Institutos, o Instituto Monitor e o Instituto Universal Brasileiro, atuam com a educação profissional a distância desenvolvendo cursos por meio de materiais impressos e via internet. O perfil atual do alunado do Instituto Universal Brasileiro é caracterizado, em sua maioria, pelas regiões Norte e Nordeste, como Faria (2010) expõe:

Atualmente o IUB atende alunos cujo perfil caracteriza maior incidência de origem nas regiões Norte e Nordeste do Brasil, que apresentam renda mensal entre 02 e 06 salários mínimos, sem profissão específica, que buscam o curso visando garantia de emprego ou crescimento na empresa. São pessoas que se encontram desempregadas e precisam da formação para candidatar-se a uma função, tendo urgência na obtenção do conhecimento e do certificado, acreditando que esta formação melhora as suas chances de conseguir uma boa colocação profissional. (FARIA, 2010, p. 120).

Esses alunos, ao matricularem-se nos cursos ofertados, encontram ambientes educacionais que procuram atender o ritmo de aprendizado individual, possibilitando o acesso aos conteúdos em qualquer tempo e lugar. Essa metodologia faz com que os alunos coloque em prática o conhecimento teórico adquirido por meio dos kits didáticos em que ele poderá praticar o ofício escolhido. Os cursos ainda contam com momento tira dúvidas no qual é possível contatar o professor por e-mail, telefone, correspondência ou presencialmente no polo de apoio. Alguns cursos contam com a realização de estágio obrigatório, o qual deverá ser realizado de forma presencial em instituições ou empresas especializadas no ramo de atividade do curso. Durante o período de estágio e ao seu término, o aluno deverá realizar relatórios que comporão parte da sua avaliação.

As avaliações têm caráter obrigatório e podem acontecer a distância com encaminhamento de formulário específico ao polo de apoio via correio ou internet, ou ainda presencialmente para o caso dos cursos técnicos em que o aluno deverá ir até os Institutos para realizá-las conforme disposto no Art. 1 o do Decreto 5.622, de 19 de dezembro de 2005. Ainda sobre esse aspecto, o 2으 parágrafo do Art. 80 da LDBEN 9394/96 regulamenta os requisitos para a realização de exame e registros de diplomas a cursos de educação a distância e os estabelecem no decreto acima 
referenciado. Por fim, a certificação é garantida aos alunos aprovados após as avaliações. O prazo mínimo para a certificação é de 60 dias e o aluno precisa agendar data e horário para retirar o seu certificado na instituição de ensino.

No Instituto Universal Brasileiro, a certificação é vinculada ao Conselho Estadual da Educação de São Paulo (CEE-SP), e no prazo de 120 dias a Instituição inscreve os alunos formandos na Gestão Dinâmica de Administração Escolar - GDAE -, órgão da referida Secretaria que facilita e integra as informações sobre educação escolar do Estado de São Paulo.

Quanto ao Instituto Monitor, o aluno recebe, após a conclusão do curso de qualificação, um certificado garantindo o direito de atuar na formação em questão. Em se tratando de curso técnico, a cada módulo concluído é expedido certificado de qualificação profissional e após a conclusão total do curso o aluno recebe o diploma de curso técnico.

Essas instituições marcaram uma época da educação a distância quando o país enfrentava problemas sociais, políticos e econômicos advindos da crise de 1929 , no entanto, sua história se mantém por meio da ocupação desse espaço, cumprindo assim uma finalidade social (FARIA, 2010). Em linhas gerais, podemos evidenciar que os dois Institutos, Monitor e Universal Brasileiro, foram pioneiros na oferta de cursos profissionalizantes na modalidade a distância, proporcionando a formação inicial e continuada à população de forma a atender à demanda do mundo do trabalho em consonância com a legislação vigente.

\section{O TELECURSO}

O Telecurso se estrutura com o auxílio do Sistema Sesi e Senai e da Federação das Indústrias do Estado de São Paulo (Fiesp) com a finalidade de desenvolver o ensino técnico do profissional brasileiro, possibilitando acesso à educação e o progresso profissional de diversas classes sociais (CARVALHO, 1999).

O programa se estruturou em 1978 com o Telecurso 2ㅇ Grau, o qual utilizava a televisão enquanto instrumento de acesso à educação para pessoas que precisavam concluir o 20 Grau. Em seguida, em 1981, o Telecurso de 2ㅇ Grau impulsionou a criação do Telecurso de 1으 Grau. A partir destes programas televisivos e da aquisição dos livros didáticos que eram vendidos em bancas e livrarias, os alunos tinham a chance de cursar e concluir a educação básica. Para diplomar-se, o aluno necessitava realizar avaliações de desempenho aplicadas em instituições da rede pública de ensino, pelas secretarias de educação dos estados ou então pelas instituições do Sistema Sesi e Senai. Em 1995, esses dois programas foram substituídos pelo Telecurso 2000, este último desenvolvido, segundo Oliveira e Castro (2001), a partir de recursos do Fundo de Amparo ao Trabalhador (FAT). O principal objetivo do Telecurso 2000, conforme documento do Senai intitulado "Manual do orientador da aprendizagem" (1995), era buscar:

[...] harmonia entre a realidade, a vida social e o mundo do trabalho. Em síntese, espera-se que o aluno tenha acesso aos conhecimentos básicos e profissionalizantes que o ajudarão a compreender a sociedade e dela participar exercendo seus direitos e deveres de cidadão - e atuar profissionalmente de modo competente e produtivo (SENAl, 1995, p. 6). 
Vale destacar que o diferencial do Telecurso 2000 foi a implantação da Metodologia de Telessalas, em que eram disponibilizados equipamentos de áudio e vídeo para transmissão das videoaulas com duração de 15 minutos e contava também com professor mediador da aprendizagem que acompanhava grupos de alunos.

O espaço da telessala era organizado a partir de salas de aulas ou locais adaptados contendo quadro, mesas, armários, cadeiras e carteiras que variavam em postos de estudo entre 20 e 40 alunos. A sala ainda contava com aparelho de televisão, vídeo cassete, a coleção completa das fitas das videoaulas, livros, dicionários, mapas e todo o material didático necessário para apoio aos alunos. Sobre os materiais do ensino profissionalizante do Curso de Mecânica, Oliveira e Castro (2001) citam que o Telecurso produziu 360 aulas, 52 vídeos e 18 livros como forma de os alunos adquirirem conhecimentos e a maior parte dos alunos envolvidos nesse projeto eram oriundos de empresas do setor industrial, o que vem reforçar a participação efetiva do Sistema Sesi e Senai enquanto propulsor desse projeto.

Sobre as instituições Sesi, Senai e Fiesp, no momento de implantação do projeto Telecurso 2000, estas dividiram atribuições. Coube ao Sistema Fiesp mobilizar as indústrias para inserir seus funcionários nos cursos ofertados. O Sesi e Senai (SP) ficaram responsáveis pela organização dos conteúdos pedagógicos, ao Sesi os conteúdos referentes ao 1o Grau e ao Senai os aqueles contemplados na habilitação profissional. Os fundamentos pedagógicos descritos no documento "Formação básica para o mundo do trabalho" baseavam-se em 04 (quatro) eixos, a saber: 1) Ensino em contexto, 2) Desenvolvimento de habilidades básicas, 3) Desenvolvimento de atitudes de cidadania e 4) Educação para o trabalho.

O primeiro refere-se à aplicabilidade daquilo que o aluno vai aprender em seu cenário real de trabalho. O segundo, por sua vez, busca desenvolver competências cognitivas e habilidades pessoais que superem o simples ato de ler, escrever e contar e propiciem ao trabalhador características exigidas pelo mercado de trabalho, tais como, criatividade, pro-atividade, capacidade de solucionar problemas entre outros. O desenvolvimento de atitudes de cidadania corresponde ao fato de os cursos proporcionarem aos alunos condições para o exercício das funções políticas, produtivas e culturais. Por último, a educação para o trabalho visa aprofundar o domínio dos alunos em aprender, transferir e aplicar os conhecimentos numa perspectiva de aprendizagem ao longo da vida.

Os documentos citados nos fazem perceber que os cursos profissionalizantes oferecidos pelo Telecurso 2000 destinavam-se a trabalhadores que almejavam ampliar seus conhecimentos e obter uma habilitação na área da mecânica industrial. Esses cursos tiveram como principal objetivo o desenvolvimento de capacidades direcionadas ao mercado de trabalho. Dentre os cursos ofertados, podemos citar: Materiais; Ensaio de Materiais; Administração da Manutenção; Automação; Higiene e Segurança no Trabalho; Organização do Trabalho; Qualidade; Desenho Técnico; Gestão de pessoas; Qualidade Ambiental; Universo da Mecânica; Normalização; Tratamento de Superfície; Tratamento Térmico; Metrologia; Processos de Fabricação; Elementos de Máquinas; Manutenção; e, Cálculo Técnico (SENAI, 1995). 
A formatação do Telecurso 2000 perdurou até o ano de 2008, quando teve sua nomenclatura modificada para "Novo Telecurso". Nesse novo formato, as disciplinas de Filosofia, Artes Plásticas, Música, Teatro e Sociologia foram inseridas por exigência do novo currículo do Ensino Médio. Atualmente, a denominação do programa é "Telecurso".

Percebemos, a partir das informações apresentadas, que o objetivo inicial do Telecurso, que é a formação para o mundo do trabalho por meio da educação a distância, permanece. O foco dos cursos se estruturou nas habilidades e competências requeridas pelo mercado de trabalho. Nesse sentido, acreditamos que o programa seja relevante por permitir o acesso à escolarização básica e profissional de forma flexível, dando possibilidades de acesso ao ensino. No entanto, a ideia da necessidade de maior escolaridade do trabalhador está sendo determinada pelas necessidades das empresas, intimamente ligada à lógica que norteia as relações capitalistas de produção.

\section{REDE e-TEC BRASIL}

Em 12 de dezembro de 2007, por meio Decreto 6.301, foi instituído o Sistema Escola Técnica Aberta do Brasil, com vistas ao desenvolvimento da educação profissional técnica na modalidade de Educação a Distância. Em 26 de outubro de 2011, pelo Decreto 7.589, da presidência da República, foi instituída a Rede e-Tec Brasil em substituição ao Sistema Escola Técnica Aberta do Brasil.

Essa iniciativa tem como foco a oferta de cursos técnicos a distância, além de formação inicial e continuada de trabalhadores oriundos do Ensino Médio ou da educação de jovens e adultos (EJA). O objetivo dessa ação é desenvolver Educação Profissional e Tecnológica na modalidade a distância e sua perspectiva é a expansão e democratização da oferta de profissionalização no interior do país, tomando como base as necessidades econômicas e sociais dos estados e as necessidades por uma formação ampla e especializada.

No que se refere à democratização do acesso ao ensino e aprendizagem, autores que pesquisam a Educação a Distância, como Belloni 2006, Pimentel 2006 e Preti 2000, afirmam que é uma modalidade viável que possibilita fazer chegar aos menos favorecidos, por razões financeiras, geográficas ou temporais, conhecimentos e habilidades necessárias para que eles possam se inserir no contexto educacional. Entendemos com isto que é legítima a preocupação com o ingresso das camadas menos favorecidas economicamente ao ensino de qualidade, além do crescimento da oferta da Educação a Distância às regiões menos providas de ensino. Nessa perspectiva, evidenciamos que todos os Estados Brasileiros são contemplados pela iniciativa Rede e-Tec.

Na home page da Rede e-Tec, ao acessar o mapa de distribuição de cursos pelos estados brasileiros, é possível encontrar a listagem completa de cidades e cursos por ela ofertados. Além disto, dados apresentados pela Rede e-Tec Brasil em fevereiro de 2013 mostram uma evolução crescente do número de matrículas e em consequência disto o aumento do número dos polos em todo o país. Ainda sobre o aspecto de distribuição de matrículas, Dourado (2005 p.11) pontua: 
O Brasil apresenta estrutura educacional descentralizada e fortemente marcada por disparidades entre as cinco regiões que o compõe (norte, nordeste, centrooeste, sul e sudeste). Desse modo, os indicadores educacionais retratam esse processo desigual e combinado e requerem políticas e gestões para a educação que considerem esse cenário na busca de alternativas e proposições educativas.

Nesse sentido, a educação a distância configura-se como um meio de abolir as barreiras de acesso ao ensino. Podemos afirmar que é uma modalidade de ensino democrática, que visa à ampliação do ensino e do conhecimento. É capaz de atender um grande número de pessoas simultaneamente em espaços e horários diferenciados, pois, utiliza de tecnologias de comunicação informação (TIC) que transpõe os obstáculos do acesso ao conhecimento.

A Rede e-Tec Brasil trouxe como principal finalidade o auxílio a alunos e professores na construção do conhecimento utilizando-se de inovações tecnológicas educacionais. Trata-se de uma iniciativa importante para a democratização do acesso ao ensino técnico público, por meio da modalidade de educação a distância, visando a profissionalização que contribua para a elevação da escolaridade, fortalecendo a continuidade de estudos de jovens e adultos em diversas cidades brasileiras.

Dentre as inúmeras avaliações realizadas pelo Sistema de Acompanhamento e Avaliação dos Cursos e-Tec (SAAS), aquela que ficou mais evidenciada foi a realizada pelos estudantes nos anos de 2011 e 2012 sobre o curso. Dados retirados do Relatório de Avaliação de fevereiro de 2013 evidenciam que os estudantes fizeram uma avaliação positiva, acreditam que os cursos ofertados pela Rede e-Tec têm atendido suas expectativas contribuindo às suas necessidades pessoais e inserindo-os no mercado de trabalho regional e local atendendo às demandas específicas. Além disso, as tecnologias utilizadas para o processo de ensino e aprendizagem são adequadas e facilitam a absorção dos conhecimentos. Quanto aos professores estes foram avaliados como sendo capacitados para o trabalho proposto pela Rede e-Tec.

A demanda por essa forma de aprendizagem cresceu e ainda crescerá, pois possibilita ultrapassar as barreiras econômicas, físicas, sociais e temporais conciliando trabalho e estudos ao longo da vida profissional.

\section{CONCLUSÃO}

Acreditamos que a modalidade de educação a distância tem conquistado nas últimas décadas um enfoque de destaque no centro das discussões pedagógicas, uma vez que torna possível o acesso de indivíduos que sem ela não teriam condições de frequentar aulas presenciais para buscar formação. A partir do levantamento da relevância da EaD no Brasil, percebemos a grande procura dessa modalidade educacional, sobretudo dos profissionais que buscam uma qualificação contínua para manter ou melhorar seus postos de trabalho, o que reflete a necessidade cada vez mais crescente da formação ao longo de toda a vida produtiva.

Nesse contexto, observamos que a educação profissional e tecnológica na modalidade a distância tem desenvolvido novos meios para atingir cada vez mais pessoas que necessitam se qualificar devido à necessidade crescente do mundo do trabalho por formação técnica e social. 
Assim, a EaD vem ao encontro das necessidades de pessoas que, por não disporem de tempo ou por longas distâncias a serem percorridas entre trabalho, escola e residência, optam por essa modalidade de ensino.

A educação profissional e tecnológica na modalidade a distância configura-se como uma estratégia de expansão do ensino, por isto acreditamos que a retomada histórica da educação profissional e tecnológica na modalidade a distância se fez necessária para compreendermos os aspectos que influenciaram o desenvolvimento dos cursos de Educação Profissional e Tecnológica nessa modalidade.

Em face ao exposto, abordar algumas iniciativas das instituições de ensino na modalidade a distância, como o Instituto Monitor e a Rede e-TEC, nos possibilitou conhecer as diversas possibilidades de formação profissional presentes no país, pois acreditamos que a população, possuidora de qualificação profissional, terá melhores condições sociais que the permitam adquirir os direitos sociais, entre os quais o trabalho. Em síntese, as questões abordadas neste artigo sobre a modalidade a distância na educação profissional e tecnológica podem servir de respaldo científico para investigações futuras, fortalecendo assim a modalidade de Educação a Distância e nos desafiando sempre a prosseguir com novos estudos.

\section{REFERÊNCIAS}

1. ALVES, Lucineia. Educação à distância: conceitos e história no Brasil e no mundo. Associação Brasileira de Educação à Distância. São Paulo. 2011.

2. BELLONI, Maria Luiza. Educação a Distância. Campinas: SP, Ed. Autores Associados, 2006.

3. BRASIL. Ministério da Educação. Lei no 9.394, de 20/12/1996. Estabelece as Diretrizes e Bases da Educação Nacional. Brasília, DF: MEC, 1996. Disponível em: <http://www2.camara.leg.br/legin/fed/lei/1996/lei-9394-20-dezembro-1996-362578publicacaooriginal-1-pl.html>. Acesso em: 4 maio 2014.

4. Ministério da Educação. Decreto no 5.622/05 de 19 de dezembro de 2005. Regulamenta o artigo 80 da Lei no 9.394/96 que estabelece as Diretrizes e Bases da Educação Nacional. Brasília, DF: MEC, 2005. Disponível em: <http://portal.mec.gov. br/seed/arquivos/pdf/dec_5622.pdf>. Acesso em: 4 maio 2014.

5. CARVALHO, Celso do Prado Ferraz de. A educação cidadã na visão empresarial: o Telecurso 2000. Campinas: Ed. Autores Associados, 1999.

6. DOURADO, Luiz Fernandes. Fracasso escolar no Brasil: Políticas, programas e estratégias de combate ao fracasso escolar. MINISTÉRIO DA EDUCAÇÃO - Secretaria de Educação Infantil e Fundamental - Departamento de Políticas Educacionais. Brasília, 2005.

7. FARIA, Adriano Antonio. $\mathbf{O}$ Instituto Universal Brasileiro e a Gênese da Educação a Distância no Brasil. Dissertação (Mestrado). Universidade Tuiuti do Paraná. Programa de Pós Graduação em Educação. 1-155. Curitiba, 2010.

8. GIL, A. C. Como elaborar projetos de pesquisa. São Paulo: Atlas, 2010.

9. LINDEN, Marta Maria Gomes Van der; ASSIS, Cibelle de Fátima Castro de. Introdução a 
Educação a Distância. Disponível em: http://portal.virtual.ufpb.br/bibliotecavirtual/files/pub_1291082475.pdf. Acesso em 28 de abril de 2012.

10. MOREIRA, Sonia Virgínia. O rádio no Brasil. Rio de Janeiro: Rio Fundo Ed., 1991.

11. OLIVEIRA, João Batista Araújo e CASTRO, Cláudio de Moura e. Uma avaliação do Telecurso 2000. Rio de Janeiro: Fundação Roberto Marinho e Banco Interamericano de Desenvolvimento, 2001.

12. PIMENTEL, Nara M. Educação Aberta a Distância: análise das políticas públicas e da implementação da educação a distância no ensino superior do Brasil a partir das experiências da Universidade Federal de Santa Catarina e da Universidade Aberta de Portugal. Tese (Doutorado em Engenharia de Produção e Sistemas - UFSC). Florianópolis, SC, 2006.

13. PRETI, Oreste (org.) Educação a Distância: construindo significados. Cuiabá: NEAD/IE - UFMT; Brasília: Ed. Plano, 2000. 268p.

14. SAAS - e-Tec. Sistema de Acompanhamento e Avaliação dos Cursos e-Tec Brasil. Relatório das Avaliações em 2011.2 - 2012.1 - 2012.2. Florianopolis, 2013.

15. SARAIVA, Terezinha. Educação a Distância no Brasil: lições da história. Em Aberto, Brasília, ano 16, n. 70, abr./jun. 1996, pg. 17-27.

16. SENAI, Serviço Nacional de Aprendizagem Industrial. Manual do Orientador de Aprendizagem. São Paulo: 1995.

17. RIBEIRO, Luis Otoni Meireles. Planejamento e gestão de um Centro de Educação a Distância (CEAD) voltado para educação profissional e tecnológica: um estudo de caso. 2008. $316 \mathrm{f}$. Tese (Doutorado em Informática na Educação) - Universidade Federal do Rio Grande do Sul, Porto Alegre, 2008.

18. TORRES, Regina Maria de Fatima. EaD no ensino profissionalizante. In: Educação a Distância: o estado da arte. São Paulo: Pearson Education, 2009. 